\title{
Does therapeutic angiogenesis overcome CKD?
}

\author{
Yoshiaki Taniyama and Ryuichi Morishita \\ Hypertension Research (2010) 33, 114-115; doi:10.1038/hr.2009.208; published online 11 December 2009
}

\section{CKD AND CHRONIC HYPOXIA}

$\mathbf{R}$ ecent studies have emphasized the role of R chronic hypoxia in the tubulointerstitium as a final common pathway in endstage renal disease, ${ }^{1}$ and showed that hypoxia in the kidney induces pro-fibrotic changes. ${ }^{2}$ Hence, oxygenation in the kidney is likely to be a critical determinant of its life. In this context, renal protective effects of angiogenic factors, such as vascular endothelial growth factor (VEGF), ${ }^{3}$ hepatocyte growth factor ${ }^{4}$ and hypoxia-inducible factor, ${ }^{5}$ are reported with some problems ${ }^{6-8}$ (Figure 1).

This issue of Hypertension Research includes a paper by Noboru Fukuda and coworkers that addresses the effect of Salll on angiogenesis. ${ }^{9}$ The Sall gene is required for multiple developmental processes, and regulates morphogenesis and organogenesis especially in the kidney. On the other hand, VEGF has a critical role in renal development by promoting endothelial cell differentiation, capillary formation and proliferation of tubular epithelial cells, so the authors investigated the relationship between Sall1 and VEGF. Sall1 gene transfer induces capillary neovascular formation in the rat cornea and mouse embryoid bodies, and increases VEGF-A promoter activity in HEK293T cells. This angiogenesis is inhibited by antiVEGF neutralizing antibody. Sall1-deficient mice show severe renal dysplasia or complete renal agenesis, but normal vascular development. ${ }^{10}$ It is unclear whether Sall1 affects vascular development, but Salll may induce renal organogenesis through angiogenic properties. SALL1 expression is reduced in patients with ${ }^{7}$ congenital dysplastic kidneys, ${ }^{11}$ as well as in congenital obstructive nephropathy $^{12}$ (Figure 2), so therapeutic angio-

Y Taniyama and R Morishita are at the Department of Clinical Gene Therapy, Osaka University Graduate School of Medicine, 2-2 Yamada-oka, Suita, Osaka 565-0871, Japan.

E-mail: taniyama@cgt.med.osaka-u.ac.jp genesis by SALL1 gene transfer may rescue the kidney in patients with CKD.

SALL1 IS A MEMBER OF SPALT FAMILY The homeotic spalt gene of Drosophila melanogaster determines the identity of the anterior head and the posterior tail regions during early development. ${ }^{13,14}$ At later stages, spalt is involved in the development of the wing disk, trachea and sensory organs. ${ }^{15,16}$ Humans and mice have four functional spalt-related genes, SALL1 to SALL4 (Sall1 to Sall4 in mice). The human SALL1 gene encodes transcription factors with a characteristic structure of evenly distributed zinc-finger domains. Human SALL1 has been described as a transcriptional repressor in a number of experimental settings, most of them involving the regulation of heterologous promoters fused to reporter genes. ${ }^{10}$ SALL1 gene expression is related to some human congenital diseases $^{11,12,15,17-19}$ (Figure 2). In particular, mutations in SALL1 result in Townes-Brocks syndrome, a rare autosomal-dominant malformation syndrome characterized by dysplastic ears, pre-axial polydactyly and/or triphalangeal thumbs, imperforate anus, renal malformations and cardiac anomalies. ${ }^{17}$ Confirming the role of Sall1 in kidney formation, SALL1 expression is reduced in patients with congenital dysplastic kidneys, a major cause of renal failure in infants, ${ }^{11}$ as well as in congenital obstructive nephropathy, a common disease affecting the fetus and young children. ${ }^{12}$

In contrast, murine Sall1 was seen to function as a transcriptional repressor of the artificial promoter containing tandem GAL4binding sites, when linked to the heterologous GAL4 DNA-binding domain, and also Sall1 was associated with HDAC and several components of the chromatin-remodeling complex. ${ }^{20,21}$ Therefore, Sall1 could repress gene expression by recruiting the HDAC complex. On the other hand, Nishinakamura et al. ${ }^{22}$ reported that the native form of Sall could function as a transcriptional activator in Wnt signaling, which is essential for many developmental processes, and that its activity correlated with its localization to heterochromatin. An increase in Sall1 proteins may squelch some transcriptional repressor complex, including HDAC, or be associated with chromatin-remodeling factors to alter the chromatin structure near the promoter region of Wnt target genes.

\section{SALL1 AND RENAL STEM CELL}

Moreover, Sall1 is necessary for the activation of some kidney mesenchymal markers, consistent with its role in ureteric bud invasion. Homozygous deletion in mice induces severe defects in the kidney, which indicates that Sall1 has an essential role in kidney development. Murine Sall1 has a role in maintaining cellular pluripotency and proliferation. ${ }^{10}$ Thus, renal primordial cells in the ureteric bud epithelium and metanephric mesenchyme are able to produce nephrons and collecting ducts when induced from pluripotent embryonic stem cells. Only cells expressing high levels of Sall1 can reconstitute a three-dimensional kidney structure in an organ culture setting, indicating that renal progenitors with multipotent capacity require Sall1. ${ }^{23,24}$ In these cells, Sall1 is not required for the generation or differentiation of renal progenitors, but for their proliferation or survival. ${ }^{23}$

\section{DOES SALL1 GENE TRANSFER OVERCOME CKD?}

Potentially, SALL1 gene transfer may improve hypoxia through VEGF-induced angiogenesis and promote renal organogenesis to counteract CKD. VEGF is an essential molecule for glomerular structure, but recently deleterious effects of VEGF have been demonstrated in diabetic nephropathy. ${ }^{6}$ Careful monitoring is therefore required in its use in CKD patients with diabetes. 


\section{Merit}

VEGF $\Rightarrow$ Angiogenesis, Anti-apoptosis

HGF $\Rightarrow$ Angiogenesis, TGF-beta inhibition

$\mathrm{HIF} \Rightarrow$ Angiogenesis,

Sall1 $\Rightarrow$ Angiogenesis, Renal stem cell?
Demerit

Diabetic nephropathy

Cystic disease?

EMT?

Diabetic nephropathy?
Figure 1 Therapeutic angiogenesis for kidney disease were reported using VEGF, HGF and HIF. Each factor has a merit and demerit. The function of sall1 is not so clear, but sall 1 may promote renal organogenesis. HGF; hepatocyte growth factor, HIF; hypoxia-inducible factor, EMT; epithelialmesenchymal transformation.

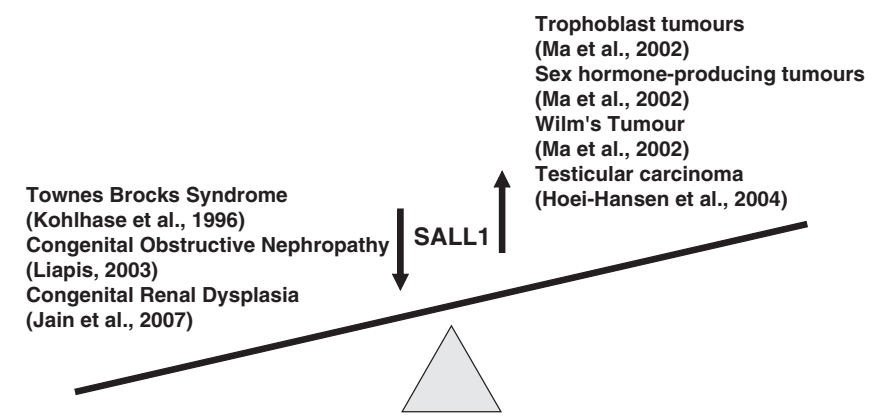

Figure 2 SALL1 expression is reduced in patients with Townes-Brocks syndrome, congenital dysplastic kidneys and congenital obstructive nephropathy. On the other hand, SALL1 expression is induced in patients with trophoblast tumors, sex hormone-producing tumors, Wilm's tumor and testicular carcinoma.

1 Eckardt KU, Bernhardt WM, Weidemann A, Warnecke C, Rosenberger C, Wiesener MS, Willam C. Role of hypoxia in the pathogenesis of renal disease. Kidney Int Supp/ 2005; 99: S46-S51.

2 Manotham K, Tanaka T, Matsumoto M, Onse T, Inagi R, Miyata T, Kurokawa K, Fujita T, Ingelfinger JR, Nangaku M. Transdifferentiation of cultured tubular cells induced by hypoxia. Kidney Int 2004; 65: 871-880.

3 Kim YG, Suga SI, Kang DH, Jefferson JA, Mazzali M, Gordon KL, Matsui K, Breiteneder-Geleff S, Shankland SJ, Hughes J, Kerjaschki D, Schreiner GF, Johnson RJ. Vascular endothelial growth factor accelerates renal recovery in experimental thrombotic microangiopathy. Kidney Int 2000; 58: 2390-2399.

4 Yang J, Dai C, Liu Y. Systemic administration of naked plasmid encoding hepatocyte growth factor ameliorates chronic renal fibrosis in mice. Gene Ther 2001; 8: 1470-1479.

5 Manotham K, Tanaka T, Ohse T, Kojima I, Miyata T, Inagi R, Tanaka H, Sassa R, Fujita T, Nangaku M. A biologic role of HIF-1 in the renal medulla. Kidney Int 2005; 67: 1428-1439.
6 Doi K, Noiri E, Fujita T. Role of vascular endothelial growth factor in kidney disease. Curr Vasc Pharmacol (in press)

7 Takayama H, LaRochelle WJ, Sabnis SG, Otsuka T, Merlino G. Renal tubular hyperplasia, polycystic disease, and glomerulosclerosis in transgenic mice overexpressing hepatocyte growth factor/scatter factor. $L a b$ Invest 1997; 77: 131-138.

8 Higgins DF, Kimura K, Bernhardt WM, Shrimanker N, Akai Y, Hohenstein B, Saito Y, Johnson RS, Kretzler M, Cohen CD, Eckardt KU, Iwano M, Haase VH. Hypoxia promotes fibrogenesis in vivo via HIF-1 stimulation of epithelial-to-mesenchymal transition. J Clin Invest 2007; 117: 3810-3820.

9 Yamamoto M, Fukuda N, Matsumoto T, Higuchi T, Ueno $\mathrm{T}$, and Matsumoto K. Zinc-finger transcriptional factor VEGF-A. Hypertens Res 2010; 33: 143-148.

10 Nishinakamura R, Matsumoto Y, Nakao K, Nakamura K, Sato A, Copeland NG, Gilbert DJ, Jenkins NA, Scully S, Lacey DL, Katsuki M, Asashima M, Yokota T. Murine homolog of SALL1 is essential for ureteric bud invasion Sall1 induces angiogenesis by activation of the gene for in kidney development. Development 2001; 128: 3105-3115.

11 Jain S, Suarez AA, McGuire J, Liapis H. Expression profiles of congenital renal dysplasia reveal new insights into renal development and disease. Pediatr Nephrol 2007; 22: 962-974.

12 Liapis H. Biology of congenital obstructive nephropathy. Nephron Exp Nephrol 2003; 93: e87-e91.

13 Jurgens G. Head and tail development of the Drosophila embryo involves spalt, a novel homeotic gene. EMBO J 1988; 7: 189-196.

14 Kuhnlein RP, Frommer G, Friedrich M, Gonzalez-Gaitan M, Weber A, Wagner-Bernholz JF, Gehring WJ, Jackle H, Schuh R. spalt encodes an evolutionarily conserved zinc finger protein of novel structure, which provides homeotic gene function in the head and tail region of the Drosophila embryo. EMBO J 1994; 13: 168-179.

15 de Celis JF, Barrio R. Regulation and function of Spalt proteins during animal development. Int J Dev Biol 2009; 53: 1385-1396.

16 Kuhnlein RP, Schuh R. Dual function of the regionspecific homeotic gene spalt during Drosophila tracheal system development. Development 1996; 122: 2215-2223.

17 Kohlhase J, Wischermann A, Reichenbach H, Froster $U$, Engel W. Mutations in the SALL1 putative transcription factor gene cause Townes-Brocks syndrome. Nat Genet 1998; 18: 81-83.

$18 \mathrm{Ma} \mathrm{Y}$, Chai L, Cortez SC, Stopa EG, Steinhoff MM, Ford D, Morgan J, Maizel AL. SALL1 expression in the human pituitary-adrenal/gonadal axis. J Endocrinol 2002; 173: 437-448.

19 Hoei-Hansen CE, Nielsen JE, Almstrup K, Hansen MA, Skakkebaek NE, Rajpert-DeMeyts E, Leffers H. Identification of genes differentially expressed in testes containing carcinoma in situ. Mol Hum Reprod 2004; 10: 423-431.

20 Netzer C, Rieger L, Brero A, Zhang CD, Hinzke M, Kohlhase J, Bohlander SK. SALL1, the gene mutated in Townes-Brocks syndrome, encodes a transcriptional repressor which interacts with TRF1/PIN2 and localizes to pericentromeric heterochromatin. Hum Mol Genet 2001; 10: 3017-3024.

21 Kiefer SM, Ohlemiller KK, Yang J, McDill BW, Kohlhase $\mathrm{J}$, Rauchman M. Expression of a truncated Sall1 transcriptional repressor is responsible for TownesBrocks syndrome birth defects. Hum Mol Genet 2003; 12: 2221-2227.

22 Sato A, Kishida S, Tanaka T, Kikuchi A, Kodama T, Asashima M, Nishinakamura R. Sall1, a causative gene for Townes-Brocks syndrome, enhances the canonical Wnt signaling by localizing to heterochromatin. Biochem Biophys Res Commun 2004; 319: 103-113.

23 Osafune K, Takasato M, Kispert A, Asashima M, Nishinakamura R. Identification of multipotent progenitors in the embryonic mouse kidney by a novel colony-forming assay. Development 2006; 133: 151-161.

24 Yamamoto M, Cui L, Johkura K, Asanuma K, Okouchi Y, Ogiwara N, Sasaki K. Branching ducts similar to mesonephric ducts or ureteric buds in teratomas originating from mouse embryonic stem cells. Am J Physiol Renal Physiol 2006; 290: F52-F60. 